\title{
An Analysis of Phonics Teaching in Mainland China
}

\author{
Min Cao \\ School of Foreign Language Studies, Henan Polytechnic University, Jiaozuo, Henan, China; \\ School of Languages, University of Portsmouth, UK
}

\begin{abstract}
This article tries to analyze the present status of phonics teaching in Mainland China by using documentary research method through sorting out all the essays about phonics teaching in CNKI (China National Knowledge Infrastructure) according to their research contents and research methods. The data collected shows that Phonics, Pinyin and IPA are mainly discussed topics, especially different roles of them in English teaching. Unfortunately, misconceptions about phonics do appear in some of those essays collected, while localization of phonics is emerging. This paper seems to shed light on a general overview of English phonics teaching in Mainland China for English teachers and researchers and cope up with the difficult points and conflicts to provide improvement for phonics teaching.
\end{abstract}

Index Terms - phonics teaching, international phonetic alphabet, Chinese Pinyin

\section{INTRODUCTION}

It is widely believed that English is a global language in a world of modern communications. As Chinese people are hungry for learning English, the Ministry of Education (2001) claimed English as a required course at grade three in primary school ever since the autumn of 2001, and suggested some well-equipped primary schools could start English class as early as grade one. Because of the national movement of English learning, the number of Chinese people who are learning English have reached more than 300 million, according to the Ministry of Education (2006). But compare with the heated hunger for learning English, nearly all of the schools teach English by using IPA (International Phonetic Alphabet), phonetic notation system that uses a set of symbols to represent each distinct sound that exists in human spoken language, because of its popularity in teaching English in China, it even grows up into a classroom instructed method. The 2011 National English Curriculum Standard (NECS) specified six objectives for reading instruction at elementary schools, two of them stated about spelling rules go like that students who complete elementary school should be able to (1) recognize words and phrases that they have learned (能认读所学词语); (2) read easy words based on spelling rules (能根据拼读的规律, 读出简单的单词). The 2011 promoted the idea of developing students' 'general understanding of spelling rules' in the level two objectives of reading, which is shown that the spelling rules must be taught in primary school. Only the spelling rules taught in primary school can the students develop the knowledge into spelling skills, and so can they reach the target of recognizing words according to its spelling rules and IPA, which is the target set for level five junior middle school phonetic knowledge.

Meanwhile at the beginning of the 21 century, the National Reading Panel in US (2000) indicated systematic instruction in phonics makes significantly greater contributions to children's development in reading, writing, spelling and comprehension. The Australian government (2005) advocated '[the children] must first master the alphabetic code via systematic, explicit, and intensive instruction in: phonemic awareness, phonics.....' (p.25). The Rose Review by Sir Jim Rose attracted government attention, and UK government proclaimed the adoption of phonics teaching and even qualified teacher status trainees should '....... demonstrate a clear understanding of systematic synthetic phonics.' (DfE, 2011, para.3) While the English-speaking countries implement effective teaching of phonics in their early reading class, Chinese teachers are struggling with IPA teaching in their class, which is partially the main cause of great burden to Chinese students. For reading instruction in primary school, IPA plays an important role in introducing words' sounds. The instruction of IPA into English teaching causes the serious phenomenon of separating sounds from their correspondent spelling, which set a man-made obstacle in learning English (Cheng \& Fan, 2011). The competitive role of IPA and Phonics in English teaching is an inevitable issue when Phonics teaching emerge. Furthermore, the previous learning experience of Chinese Pinyin (a Chinese phonetic spelling system, the means by which a character can be $\mathrm{read} /$ pronounced), cannot be denied in the learners' English learning life, the correlation between the two learning experience should be considered. This article tends to analyze the present status of phonics teaching in China through sorting out the data collected on CNKI ever since the publication of the first introduction about phonics in China.

\section{Phonics Teaching in Mainland China}

\section{A. Data Collection}


The data about Phonics used in this article is collected through the browse for phonics or 自然拼读 (natural phonics, the Chinese corresponding translation of phonics) in CNKI. Nearly two hundred essays are accumulated, and after reading through each paper only ninety-four papers are seen to be closely relative with phonics or phonics teaching in China. In the following part of the paper their content and researches will be analyzed. From Figure.1, it is likely to be seen that the first introduction of phonics in China appeared in 2005, and the numbers of paper are growing increasingly in recent years, especially in 2016 there are twenty-seven papers published before October the data was collected, which shows the increase number of English teachers and researchers who pay their interest to Phonics teaching.

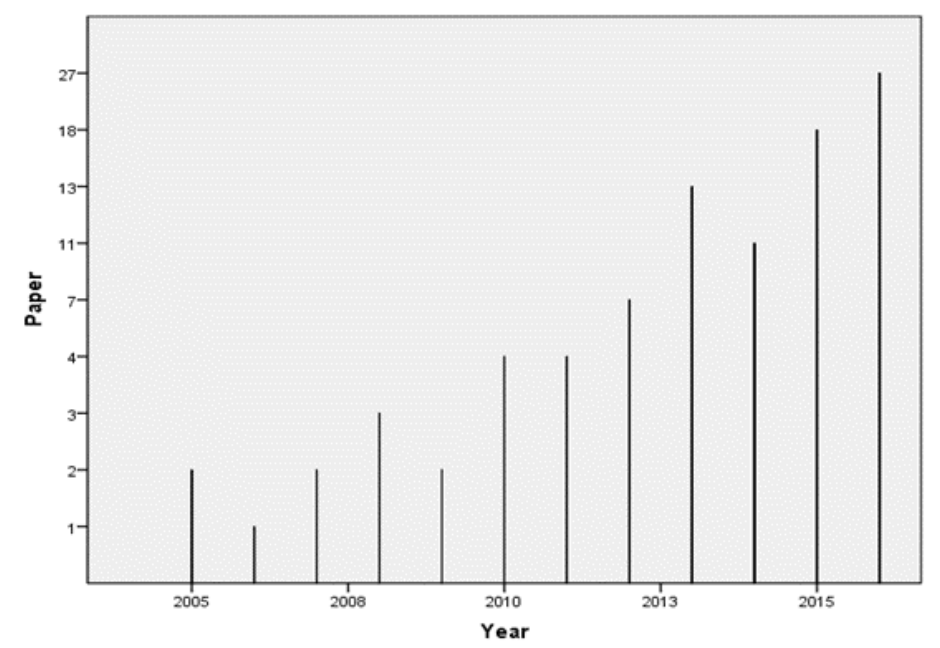

Figure 1. The Number of the Papers Published Each Year in CNKI About Phonics

\section{B. The Topic Issues in the Qualitative Researches}

While sorting out these ninety-four papers collected on CNKI, they could be generally divided into qualitative researches and quantitative researches according to the research method adopted in the paper. As for the content of the qualitative research papers, it could be lined up to discuss the different role of Phonics and IPA, the transference from Chinese Pinyin, and misconceptions about phonics. While in the quantitative researches, the research mostly done about the phonics in elementary schools, colleges and universities.

(1).Phonics and Pinyin

While learning the correspondence between letters and their represented sounds, the role of the Chinese students' first letter-sound pair, Pinyin, must be considered. Chen (2012) stated that English teachers in elementary schools should take the advantage of the Chinese Pinyin they have mastered, and make use of its positive transfer into English phonetic teaching, and apply the similarity between them in pronunciation into teaching the spelling rules about the consonant and consonant groups in English to lay a foundation for vocabulary memorization. Similar findings have been made in

Chen (2016) and Qi \& Cui (2016). Chen (2016) further suggested that English teachers should try to compare the Chinese Pinyin initials with English consonants and turn students' Pinyin knowledge into their ability of recognizing English words. Qi \& Cui (2016) further proposed that when start to teach the sounds of 26 English letters the sound of consonants such as, b, p, m, f, d, t, n, l, g, k, h, j, q, x ..... should be taught first by following the same order of the Chinese Pinyin initials. However, most of these studies were based on the assumption that Chinese Pinyin might have positive effect on English learning experience, no researches have discussed the negative effect of Chinese Pinyin in English Phonics learning, which could cause great difficulty for their English learning. Furthermore, since the Chinese students have mastered the blending and segmenting of sounds in Chinese Pinyin practice, they have built a solid foundation of phonemic awareness for English learning. It might be claimed that it is students' phonemic awareness should be transferred into their English learning.

(2). Phonics and IPA

After the introduction of Phonics in mainland China in 2005, the role of Phonics teaching and IPA teaching in English instruction has been disputed. Gao (2005) stated that IPA bases on another written symbol to represent phonemes in English, which is undoubtedly a burden for the students in the primary school if they are taught in English. She further proposed that once students learn about Phonics, the defects of mismatching sounds and spelling brought by IPA teaching could be made up. Similar findings have been made by Wu (2011) and Lei (2006). Other studies have shown that Phonics and IPA teaching are not contradictory, they are complementary with each other, and should be combined with each other to reach an ideal efficiency in English teaching (Hu, 2012; Leng, 2012; Xu, 2011; Chen \& Zhang, 2011; Liang \& Meng, 2010; Yu, 2013; Zhang, 2015). Some researchers (Chen \& Zhang, 2011; Wang, 2013) further proposed that Phonics is the prelude to IPA learning, for the children at lower grade, learning an independent phonetic system along with the English letter systems is not only a great burden, but also the main cause of reducing 
interest and activity in English learning, while phonics could help young children remember vocabulary easily. on the contrary, for the children at higher grade, since they start to contact words with more syllables and irregular words that do not follow the spelling rules, it could be more helpful if they could learning IPA. However, most of these studies were based on the assumptions that Phonics cannot deal with the words with more syllables and irregular tricky parts, Phonics is only helpful in being an assistant tool to memorize vocabulary. In fact, recent studies indicate that Phonics deals with speaking, listening, writing and grammar, and it has taken tricky words into consideration by emphasizing the tricky bits in a word (Waugh, D \&Harrison-Palmer, R, 2013; Jolliffe, W. \& Waugh, D. with Carss, A., 2012).

(3).Misconceptions about Phonics

From the introduction of the papers about phonics and phonics teaching in Mainland China, misconceptions about phonics could be widely seen in the previous essays which support combination with IPA. Uppermost the misconception goes that phonics is just letter-sound correspondence. This view is supported by Zang (2014) who discussed the shortages of phonics and stated that there are a great number of words whose spelling do not meet with the spelling rules in phonics (irregular words or tricky words). She further claimed that phonics is not applicable for English learners at all range of ages in China, because of the fact that for the children at young age their knowledge of phonics will influence their later Chinese Pinyin learning, and phonics could reduce the learning efficiency of those students at higher grade who have learned IPA. Moreover, Wang (2015) stated that English teachers should be aware that phonics is a method for teaching children in English-speaking countries for improving their reading efficiency, while IPA is invented for learners in non-English-speaking countries. It might be claimed that some English teachers and researchers in Mainland China have not been well informed about Phonics.

\section{(4). Quantitative research}

Among all the ninety-four papers on phonics, most of them are qualitative researches, only ten papers are concerned about quantitative research. In the quantitative researches collected, three papers published on the quantitative researches done in elementary school, the rest seven researches are done about the phonics teaching in colleges and university.

For the quantitative researches carried about in elementary school Yang (2011) conducted a research by collecting empirical data from the control group given lessons through traditional letter teaching method and the experimental group in phonics class. After ten weeks of teaching, the results conveyed that the students in phonics class made obvious progress in post-tests, which indicated the feasibility of phonics teaching in primary school. Conversely, in Yang's research no significant different is found between IPA teaching and phonics teaching, both of the two groups make great progress after systematic teaching. The difference lies in that phonics teaching is much easier than IPA who uses two phonetic systems. In contrast to Yang (2011), Ding (2015) carried out a research to test the efficiency of phonics teaching in a primary school, it finds that the students taught by phonics performed significantly better in recognition of extending new words in listening and reading than the counterparts in look-and-say class. While there is no significant difference shown on recognition of known words.

The students' comparatively low proficiency in recognizing words, reading and listening arouse some English teachers in colleges and universities conduct research about phonics teaching. Liu (2009) applied phonics teaching method into the English teaching of Art College students, it is found that phonics teaching could help the college students improve a lot in recognition, writing words and even their reading ability. Coincidentally, similar researches have been done by Su (2012), Zhu (2013), Yuan (2013), Ren \& He (2014), and Feng (2015). Su (2012) conducted a research among 46 freshmen non-English majors who are found lack the awareness of letter-sound correspondence. The results showed that the students in the phonics teaching class improve efficiently in recognizing words, whereas their improvement in listening cannot be seen easily. Zhu (2014) found phonics teaching could help the college students accumulate English vocabulary by establishing the correspondence between sounds and letter. Ren \& He (2014) proved that implicit language knowledge (Phonics) learning improves in vocabulary autonomous learning ability in the audio visual context and examines the effectiveness and necessity of learning Phonics in English pronunciation and intonation courses.

(5) Localization of Phonics

In Mainland China, the idea of localization of phonics is supported by Wang (2015) who proposed a simplified empirical solution of phonics by corresponding the 26 alphabets with 38 IPA written symbols reduced from the previous 48 symbols. She further stated that when present a sound all the letters or letter groups share the same sound should be presented at the same time. As such, the solution probably suggest that IPA should be taught to students with their representative letter or letter groups, it might claim that IPA and Phonics should both be taught, which inevitably increase the burden to students. Another method is proposed in Zhang (2015) to help students improve their pronunciation and memorize vocabulary, students are trained through reading consonants, vowels and the vowel and consonant pair such as, ber, bar, bor, bing, mer, mar, mor, ming; ner, nar, nor, ning; ble, ple; mal, fal; ab, eb, ib, ob, ub, which are described like Chinese radicals, could be used to form words. For example, 'morning', as she stated, could be formed by putting 'mor' and 'ning' together. This method probably suggest that students' phonemic awareness, ability of segmenting and blending sounds are not part of the English teaching. However, grammar, spelling, listening and writing, components of Phonics teaching, are not included in the previous localized teaching methods. 


\section{IMPLICATIONS AND LIMITATIONS}

Previously, this paper tends to analyze the qualitative and quantitative researches of Phonics teaching in Mainland China, after sorting out the introduction of phonics in Mainland China, it could be shown that English teachers and researchers are not fully informed of Phonics which affects every aspect of English learning - pronunciation, spelling, reading and grammar, let alone the benefits of teaching Phonics to children. It is impossible to teach IPA system to young children, especially English as a foreign language. Since they are still confused about the basic twenty-six letters and introducing the IPA symbols will bring more confusion. It is a shortcut or direct way to reading by paying attention to the letters and their sounds rather than consulting another complicated system. It is likely to read with Phonics by firstly trying to analyze the sounds made by individual letter or letter groups. If the word is an irregular one, after making an educated guess the dictionary could be looked for confirmation.

The first important thing should be done is to introduce objectively the theories and practices of Phonics teaching into Mainland China by publishing essays or training, especially to English teachers in the countryside or remote areas. Once they learn the systematic phonics teaching encourage more English teachers try to implement Phonics teaching to their classroom teaching and share their successes and failures with other colleagues or English teachers in their area. Phonics learning is based on wide ranges of phonics reading and practice. Level reading textbooks and extracurricular readings should be developed with the arrangements of Phonics teaching. Great number of level readings such as, Oxford Reading Tree, Ladybird Reading a have been brought into China, it seems better to produce level reading for Chinese English learners. It could be found that the spelling rules, phonemic awareness should be mastered by the students in elementary school are still discussed in high school or college. English teachers in the universities still make up the lessons for English pronunciation which should be well mastered before middle school. English learners in Mainland China could understand texts well but not speak in English. All of these are worth being reflected by English teachers, researchers and English education policy makers. One of the issues attracts attention is the smooth transition from English teaching in elementary school to English teaching in middle school and then to college and university. The English curriculum standard must be clearly described and well designed for each grade, even be specific to each teaching term, week and hour. And correspondingly, scientific assessments should be applied into each unit.

Since the author is not an English teacher in elementary schools, the present status of Phonics teaching in Mainland China could only be accessed through collecting and analyzing all the essays published on CNKI, it seems that limitations can not be avoided. Certain limitations arise from methodology, that is, data collection and analysis. Considering the information about Phonics teaching in Mainland China could be gained through synchronic and diachronic study, documentary research method is the only way appropriate. The data collected is not enough to describe the picture of the Phonics teaching in Mainland China wholly. Limitations of this study promise some followup researches. The topics discussed in the Phonics teaching in Mainland China are hopefully the topics for future study. For example, it is a good topic to discuss the bi-directional transfer between Phonics teaching and Chinese Pinyin, for Phonics teaching when it will be proper? If the children start to learn Phonics when they have learned Chinese Pinyin, will Chinese Pinyin influence their Phonics learning and how does it happen? On the contrary, if the children start learning Phonics and Chinese Pinyin at the same time, what will happen? Actually there are numerous experimental studies to be conducted. In this way, the Phonics teaching in Mainland China will be more effective and efficient.

\section{ACKNOWLEDGMENT}

This research was supported by the China Scholarship Council; Soft Science Project of Henan Province 'Research on the integration and development of the folk cultural resources in Central Plains (122400450577).' The 12th Five-year Plan of Henan Science of Education (2015-JKGHYB-0063); The College Teaching Reform Project in Henan Polytechnic University (2015JG007; 2015JG086).

\section{REFERENCES}

[1] Australian Government, Department of Education, Science and Training. (2005). Teaching reading: Report and recommendations. National enquiry into the teaching of literacy. Barton: Department of Education, Science and Training.

[2] Chen, M. X. (2016). Sige zhuzhong tigao ziran pindufa zai xiaoxue yingyu jiaoxue zhong de youxiao yingyong. [Four attentions for the effective application of Phonics in English teaching in elementary school]. Learning Weekly 10. 30,128-29. DOI: 10.16657/j.cnki.issn1673-9132.2016.30.082.

[3] Chen, W. D. (2012). Liyong Phonics jinxing xiaoxue yingyu yuyin rumen jiaoxue de tansuo. [Exploration of Phonetic teaching by using Phonics in elementary school]. Primary School Teaching Research 9, 38-39.

[4] Chen, Y. J. \& Zhang, Z. H. (2011). Qianxi ziran pinyin yingyu jiaoxue fa [A brief analysis of Phonics teaching]. Journal of Sichuan College of Education 27. 3,106-09.

[5] Chen, Y. J.\& Zhang, Z. H. (2011). Qianxi Ziran pinyin yingyu jiaoxuefa. [A tentative discussion on Phonics]. Journal of Sichuan College of Education 27. 3, 106-09.

[6] Cheng, M. S. \& Fan, W. F. (2011). Linking the Sounds with the Spelling in Learning English Words: Using Natural Pronunciation Symbols. Foreign Languages in China 8. 4, 76-81. DOI:10.13564/j.cnki.issn.1672-9382.2011.04.015.

[7] D, Z. J. (2015). Zoujin ziran pindu de shijie zhanxian yuyin jiaoxue xinmeili—Xin jiaocai Beijingxia xiaoxue san si nianji yuyin Phonics Jiaoxuefa de youxiaoxing tanjiu. [Showing the new charm in Phonetic teaching by walking into the world of 
Phonics — The effectiveness of Phonics teaching in pronunciation teaching for Grade three and Grade four students in elementary school under the background of new textbook]. English Teachers 2, 32-36.

[8] DfE. (2011). Teachers' Standards in England from September 2012. London: Department for Education.

[9] Feng, Y. L. (2015). Mianxiang Phonics de gaozhi xumushouyizhuanye yingyu yuedu yishi peiyang. [Cultivating English reading awareness of the students majoring in Animal Science and Veterinary Medicine]. Heilongjiang Animal Science and Veterinary Medicine 11,175-76. DOI:10.13881/j.cnki.hljxmsy.2015.2008.

[10] Gao, M. (2015). Ziranpindufa zai xiaoxue yingyu jiaoxuezhong de yingyong. [Application of Phonics in English teaching in elementary school]. Journal of Basic English Education 7. 6, 62-64.

[11] $\mathrm{Hu}$, C. J. (2012). The Comparison and Application of Phonics and Phonetic Teaching in Children's English Teaching. Journal of Anhui University of Technology (Social Sciences) 29. 3, 121-123.

[12] Jolliffe, W. and Waugh, D. with Carss, A. (2012). Teaching Systematic Synthetic Phonics in Primary Schools. London: Learning Matters SAGE.

[13] Lei, J. (2006). Xiaoxue yingyu jiaoxue fangfa erze. [Two English teaching methods in elementary school]. Jiaoyukexuelunta 5, 77.

[14] Leng, Y. (2012). Qiantan ziran pindufa yingyong wuqu. [Discussion on natural Phonics application error]. Journal of Jiamusi Education Institute 9, 292.

[15] Liang, Y. Z \& Meng, Y. N. (2010). Yingyu guojiyinbiao yu ziran pindufa de bijiao. [A comparative study of international English Phonetics and Phonics]. Journal of Foshan University (Social Science Edition) 28. 5, 93-96.

[16] Liu, L. (2009). Natural Phonics Arts Colleges in the English Teaching. Journal of Anshun University 5, 54-56.

[17] Ministry of Education. (2001). Jiaoyubu guanyu jiji tuijin xiaoxue kaishe yingyu kecheng de zhidao yijian. [MOE guidelines for actively promoting the offering of English classes in elementary schools]. Retrieved October 30, 2006, from http://www.edu.cn/20010907/3000637.shtml.

[18] Ministry of Education. (2006). Quanguo yueyou 3 yi duo ren xue yingyu, zhan zong renxu de 1/4. [More than 300 million people are learning English in China, which is $1 / 4$ of the total Chinese population] Retrieved March 9, 2007, from http://www.edu.cn/20060328/3181348.shtml.

[19] Ministry of Education. (2012). Yiwujiaoyu yingyu kecheng biaozhun (2011 Version). [National English Curriculum Standard]. Beijing: Beijing Normal University Press.

[20] National Institute of Child Health and Human Development. (2000). Report of the National Reading Panel. 'Teaching children to read: An evidence-based assessment of the scientific research literature on reading and its implications for reading instruction' (NIH Publication No. 00-4769). Washington, DC: US Government Printing Office.

[21] Qi, Z. W. \& Cui, X. M. (2016). Jiyu ziran pindu fa de xiaoxue dinianduan yingyu cihui xuexi lujing tanjiu. [A tenatative study on ways of learning English words based on Phonics]. Journal of Mudanjiang College of Education 3, 112-13.

[22] Ren, Y., \& He, G. D. (2014). An Empirical Study on the Effectiveness of Phonics Learning and Indirect Vocabulary Acquisition. Foreign Language Research 5,117-120. DOI:10.16263/j.cnki.23-1071/h.2014.05.034.

[23] Rose, J. (2006). Independent Review of the Teaching of Early Reading, Final Report, March 2006 (The Rose Review - Ref: 0201-2006DOC-EN). Nottingham: DfES Publications.

[24] Su, C. H. (2012). Tigao daxuesheng yingyu pindu he tingxie nengli de tujing--ziran pindufa. [The way to improve university students' spelling and dictating-Phonics]. English Teachers 7, 38-41.

[25] Wang, K. (2015). Qiantan shaoer yingyu jiaoxue__ Ziran pindu fa. [A brief introduction of English teaching for childrenPhonics). Early Childhood Education 4, 22. DOI:10.16550/j.cnki.2095-9214.2015.10.031.

[26] Wang, M. L. (2013). Qiantan ziran pindufa yu yinbiao jiaoxue zai xiaoxue yingyu jiaoxue zhong de fenjieduan yunyong. [A brief introduction of Phonics and IPA teaching in different phrases of English teaching in elementary school]. Jian Nan Wen Хие 2,390-391.

[27] Waugh, D \& Harrison-Palmer, R. (2013). Teaching Systematic Synthetic Phonics. London: Learning Matters SAGE.

[28] Wu, J. (2011). Early English Reading and Spelling Teaching. The Guide of Science \& Education 10, 32-33. DOI:10.16400/j.cnki.kjdkz.2011.10.033.

[29] Wu, X. F. (2016). Qiantan ziran pindu fa zai xiaoxue yingyu jiaoxue zhong de yingyong. [A briefintroduction of the application of Phonics in English teaching in elementary school]. Education for Chinese After-school (Theory) 5, 96-98.

[30] Yang, Q. Z. (2011). English Phonetics Teaching in Primary School: The Empirical Research on Phonics and Letter Teaching. Journal of Harbin University 32. 8, 109-112.

[31] Yu, F. (2013). Qianxi zhengque shiyong ziran pindu dui kouyu de zhongyao zuoyong. [A brief analysis of the great importance of Phonics teaching in improving speaking].Intelligence 14,195.

[32] Yuan, G. H. (2013). Ziran pindufa zai shifansheng cihui pinxie nengli zhong de yunyong. [The application of Phonics to improve students' skill of spelling vocabulary in normal college]. Overseas English 12,120-21/125.

[33] Zang, P. (2014). Ziran pindu fa-Xiaoxue yingyu ketang shang de shuangrenjian. [Phonics: A double sword in elementary English class]. Learning Weekly 7, 136. DOI:10.16657/j.cnki.issn1673-9132.2014.19.053.

[34] Zhang, J. (2015). Tongguo IPA he Phonics gongjian gaozhi xuesheng yingyu danci pindu pinxienengli. [Establish students' skills of reading and spelling through IPA and Phonics teaching in college]. English Square 2,142-143. DOI: 10.16723 /j. cnk i. yygc. 2015. 02. 076.

[35] Zhu, Y. (2014). Gaozhi xiao yingyu ziran pindu jiaoxue de shizheng yanjiu. [An empirical study of Phonics teaching in college English teaching]. Journal of HuBei TV University 34.12, 33-34.

Min Cao was born in Anyang, Henan province, China in 1981. She received her Master Degree of Foreign Linguistics and Applied Linguistics from Southwest University, China in 2009.

She is currently a lecturer in Henan Polytechnic University, Jiaozuo, Henan Province, China. Her research interests include Second language Acquisition, English Language Teaching, and Intercultural Communication. 